Tropical Journal of Pharmaceutical Research February 2016; 15 (2): 221-229

ISSN: $1596-5996$ (print); 1596-9827 (electronic)

(C) Pharmacotherapy Group, Faculty of Pharmacy, University of Benin, Benin City, 300001 Nigeria.

All rights reserved.

Available online at http://www.tjpr.org

Original Research Article

http://dx.doi.org/10.4314/tjpr.v15i2.2

\title{
Preparation and Evaluation of Alcohol-Alkaline-Treated Rice Starch as a Tablet Disintegrant
}

\author{
Yanisa Boonwatcharapan', Pathomthat Srisuk', Pasquale Palladino ${ }^{2,3}$, \\ Saengrawee Sutthiparinyanont ${ }^{4}$ and Padungkwan Chitropas ${ }^{1 *}$ \\ ${ }^{1}$ Faculty of Pharmaceutical Sciences, Khon Kaen University, Khon Kaen 40002, Thailand, ${ }^{2}$ Department of Chemical Sciences, \\ University of Catania, Viale A. Doria 6, 95124, Catania, ${ }^{3}$ I.N.B.B. Consortium, Viale delle Meglie D'Oro, 305, 00136, Roma, \\ Italy, ${ }^{4}$ School of Pharmacy, University of Phayao, Phayao 56000, Thailand
}

*For correspondence: Email: padchi@kku.ac.th; Tel: +66-43362092

Received: 24 July 2015

Revised accepted: 26 December 2015

\begin{abstract}
Purpose: To prepare and characterize alcohol-alkaline modified rice starch (MRS) as a disintegrant for tablets.

Methods: The preparation of MRS was carried out using $3 \mathrm{M} \mathrm{NaOH}$ and $40 \%$ ethanol solution. Characterization carried out for MRS include morphology, swelling capacity, thermal and pasting properties. Direct-compressed tablets (DCT) containing either propranolol hydrochloride (PPNL) or hydrochlorothiazide (HCTZ) were evaluated for hardness, friability, disintegration time and drug release. Results: The microstructure of MRS was different in shape and dimension from that of rice starch (RS). The absence of gelatinization endotherm and FT-IR spectral peak for MRS correlated with change in MRS structure and arrangement. MRS showed significantly higher swelling capacity $(p<0.05)$ than RS, and also proved to be a disintegrant in DCT. The disintegration time of the tablets containing MRS was lower in the presence of large particles (3.55 $\pm 0.56 \mathrm{~min})$; high content of MRS (1.03 $\pm 0.06 \mathrm{~min})$; low content of lubricant $(3.16 \pm 0.44 \mathrm{~min})$; water soluble filler $(1.55 \pm 0.16 \mathrm{~min}$ for Super-tab®); and model $\operatorname{drug}(0.84 \pm 0.09$ min for HCTZ) $(p<0.05)$.

Conclusion: MRS exhibits improved water solubility and swelling capacity compared with RS, and is thus a good disintegrant for direct-compressed tablet formulations, especially in the presence of water insoluble fillers.
\end{abstract}

Keywords: Rice starch, Alcohol-alkaline treatment, Disintegrant, Directly-compressed tablet, Insoluble fillers

Tropical Journal of Pharmaceutical Research is indexed by Science Citation Index (SciSearch), Scopus, International Pharmaceutical Abstract, Chemical Abstracts, Embase, Index Copernicus, EBSCO, African Index Medicus, JournalSeek, Journal Citation Reports/Science Edition, Directory of Open Access Journals (DOAJ), African Journal Online, Bioline International, Open-J-Gate and Pharmacy Abstracts

\section{INTRODUCTION}

Fast-release tablet is one of the widely used dosage forms for oral administration because of convenience and short onset of action, and tablet production by direct compression method is very popular due to the simplicity, low cost and efficiency [1]. Disintegrants are very important substance required for the fast-release of active constituents from tablet dosage forms because they facilitate the rapid breaking of the tablet into smaller particles [2]. Several compounds have been reported for use as tablet disintegrants including starch, cellulose, povidone and their derivatives [3]. Starch is a natural polymer which is widely employed in pharmaceutical formulations before or after physical and/or chemical modifications with the aim of improving its ability to swell in water, and to confer higher hardness and lower friability to the tablets [4-7]. 
Alcoholic-alkaline treatment is a simple and inexpensive method of the modification of starch that confers better swelling and higher water solubility at room temperature [6]. This method has been used to modify several starches, such as corn starch, waxy corn starch and sago starch $[6,8,9]$. Modify waxy maize starches by the method was used as a controlled release matrix [10]. This study focuses on rice starch (RS) that is safe, inexpensive and an important agricultural product of Thailand. RS can be used as pharmaceutical excipient, such as tablet filler in powder form and tablet binder after pregelatinization by heating $[10,11]$. Unfortunately, RS cannot be used as a disintegrant in tablet because it cannot swell and it is insoluble in water. Thus, the RS modification could possibly improve swelling and water solubility for use in this purpose.

The aim of this study was to investigate the tableting properties of alcoholic-alkaline modified rice starch (MRS) as a disintegrant.

\section{EXPERIMENTAL}

\section{Materials}

Ethanol $(95 \%)$ was purchased from the Liquor Distillery Organization, Thailand. Methanol and citric acid monohydrate were obtained from Prolabo®, EC. Other chemicals and solvents including $\mathrm{NaOH}(\mathrm{RCl}$ Labscan, Thailand), and hydrochloric acid (Lab-Scan, Ireland) were of analytical grade. Propranolol hydrochloride (PPNL, Changzhou Yabang, China), hydrochlorothiazide (HCTZ, Suzhou Ausun Chemical, China), partially pregelatinized maize starch (Starch 1500®, Rama Production, Thailand), agglomerated lactose (Super-tab $\AA$, Meggle, Germany), dibasic calcium phosphate (Di-comprez $\AA^{\circledR}$, Sudeep Pharma, India), rice starch (Thai Flour Industry, Thailand), sodium starch glycolate (Explotab ${ }^{\circledR}$, Rama Chem, Thailand), colloidal silicon dioxide (Aerosilß 200, Evonik Industries AG, Germany) and magnesium stearate (Fluka Chemika, Switzerland) were of commercial grade.

\section{Preparation of MRS}

MRS was prepared by a method of Chen and Jane [6]. A $200 \mathrm{~g}$ of rice starch were suspended in $2000 \mathrm{~g}$ of $40 \%$ ethanol solution in a blender mixer for $15 \mathrm{~min}$. Subsequently, the mixture was vigorously stirred with $800 \mathrm{~g}$ of $3 \mathrm{M} \mathrm{NaOH}$ solution for $90 \mathrm{~min}$. Thereafter, $95 \%$ ethanol $(1600 \mathrm{ml})$ was added to the mixture and stirred for $15 \mathrm{~min}$ at ambient temperature. The solid sediment was allowed to settle and the supernatant was decanted. The precipitate was collected, re-dispersed in $1200 \mathrm{ml}$ of $40 \%$ ethanol solution, and neutralized with $0.5 \mathrm{M}$ citric acid in $800 \mathrm{ml}$ of ethanol. The neutralized starch was collected by filtration and washed using 40 $\%$ ethanol and $95 \%$ ethanol, respectively. The filtered MRS obtained was dried in a hot air oven at $50{ }^{\circ} \mathrm{C}$ for $24 \mathrm{~h}$. It was milled, sieved (Nos. 100, 140 and 200 meshes), kept in aluminium foil bag, and stored in desiccators at ambient temperature.

\section{Evaluation of MRS}

\section{Particle morphology}

Shape and size of RS and MRS were observed using scanning electron microscopy (SEM, model JSM-5410LV, JEOL, Japan). Starch sample was mounted onto stub, coated with gold using low vacuum sputter coating, and viewed using the scanning electron microscope.

\section{Differential scanning calorimetry (DSC)}

Thermal properties of RS and MRS were analyzed by a differential scanning calorimeter (Model DSC 822, Mettler Toledo, Switzerland). Starch samples (3 $\mathrm{mg}$ ) were accurately weighed in an aluminum pan, and then $7 \mu \mathrm{L}$ of purified water was added. Subsequently, the samples were hermetically sealed and allowed to stand for $60 \mathrm{~min}$ at room temperature prior to recording the thermogram by heating the sample of starch at a rate of $10 \stackrel{\circ}{\circ} / \mathrm{min}$ from $30-120 \stackrel{\circ}{\circ}$, and DSC thermograms were recorded.

\section{Fourier transform infrared (FTIR) spectroscopy}

The spectra of RS and MRS were analyzed by FTIR spectrophotometer (Spectrum One, Perkin Elmer, U.S.A). The starch samples were ground with a mortar and pestle together with dried $\mathrm{KBr}$ $(1: 10 \mathrm{w} / \mathrm{w})$, compressed to a disk and analyzed between wave numbers of 4000 and $450 \mathrm{~cm}^{-1}$ at a resolution of $4 \mathrm{~cm}^{-1}$.

\section{Swelling capacity}

Starch $(0.2 \mathrm{~g})$ was poured into a graduated cylinder $10 \mathrm{ml}$ and recorded the volume $\left(\mathrm{V}_{0}\right)$. Ten milliliters of distilled water, $0.1 \mathrm{M} \mathrm{HCl}$ or $\mathrm{pH} 6.8$ phosphate buffer were added. The sample was kept at ambient temperature for $24 \mathrm{~h}$ and recorded for the final volume $\left(V_{1}\right)$ of the starch gel in the cylinder. Swelling capacity was 
calculated as a ratio of $\mathrm{V}_{1} / \mathrm{V}_{0}$ with three replicates.

\section{Effect of formulation factors on tablet properties}

Disintegrant type, particle size and MRS content, lubricant content, filler type and drug type were studied. The tablets were prepared by direct compression method using hydraulic press with $10 \mathrm{~mm}$ diameter flat face punch at $100 \mathrm{kgf} / \mathrm{cm}^{2}$. The tablet samples were evaluated for their physical properties such as hardness, friability, disintegration time and dissolution time.

To study effect of disintegrant type, MRS, RS and sodium starch glycolate (Explotab®) were used as disintegrants. Each tablet contained 350 $\mathrm{mg}$ of Di-Comprez®, $2 \% \mathrm{w} / \mathrm{w}$ of disintegrant, 1 $\% \mathrm{w} / \mathrm{w}$ of colloidal silicon dioxide and $2 \% \mathrm{w} / \mathrm{w}$ of magnesium stearate. The effect of particles size of MRS was studied for diameters of < 75, 75 106, 106 - $150 \mu \mathrm{m}$ with the same amount of DiComprez®, disintegrant, colloidal silicon dioxide and magnesium stearate.

Three types of fillers, at $350 \mathrm{mg}$ per tablet, were used: Di-Comprez®, Super-tabß, and Starch® 1500. Each formulation contained $2 \% \mathrm{w} / \mathrm{w}$ of MRS, $1 \% \mathrm{w} / \mathrm{w}$ of colloidal silicon dioxide and $1 \%$ $\mathrm{w} / \mathrm{w}$ of magnesium stearate.

The effect of MRS content was assessed concentrations of 2, 4, and $8 \% \mathrm{w} / \mathrm{w}$. Each tablet contained the same ingredients, viz, $350 \mathrm{mg}$ of Di-Comprez®, $1 \% \mathrm{w} / \mathrm{w}$ of colloidal silicon dioxide and $1 \% \mathrm{w} / \mathrm{w}$ of magnesium stearate.

Three concentrations of magnesium stearate at 1,3 and $5 \% \mathrm{w} / \mathrm{w}$ were used to study the effect of lubricant concentration on tablet properties. Each tablet contained $350 \mathrm{mg}$ of Di-Comprez®, $2 \%$ $\mathrm{w} / \mathrm{w} \mathrm{MRS}$, and $1 \% \mathrm{w} / \mathrm{w}$ colloidal silicon dioxide.

To study the effect of drug types, propranolol hydrochloride (PPNL) $40 \quad \mathrm{mg}$ or hydrochlorothiazide (HCTZ) $50 \mathrm{mg}$ were used. Formulation of each tablet contained drug, DiComprez®, $4 \%$ w/w MRS, $1 \%$ w/w colloidal silicon dioxide and $1 \% \mathrm{w} / \mathrm{w}$ magnesium stearate.

\section{Tablet evaluation}

Tablet hardness was measured $(n=10)$ by a tablet hardness tester (Model VK 200, Vankel®), Benchsarer TM Series, USA). Tablet friability was tested using a friability tester (Model Friabilator, Vankel®, USA) based on USP 34/NF 29 [12]. The disintegration time of tablets was evaluated ( $n=6)$ using a disintegration apparatus (model QC21, Hanson® Research, USA).

Drug dissolution of PPNL and HCTZ tablets were assessed $(n=6)$ using a USP type 2 dissolution test apparatus (Hanson Research, Northridge, CA, USA). Drug concentration in dissolution medium was analyzed spectrophotometrically (model UV-1201, Shimadzu, Japan) at 289 and $272 \mathrm{~nm}$ for PPNL and HCTZ, respectively.

\section{Statistical analysis}

Statistical analysis of the data obtained was carried out using one-way analysis of variance (ANOVA) at $95 \%$ confidence level $(p<0.05)$. Significant differences of mean values were determined by Scheffe's test. The SPSS version 16.0 for windows was used to determine.

\section{RESULTS}

\section{Characteristics of RS and MRS}

\section{Morphology}

RS particles had a polygonal shape with 3 - 10 $\mu \mathrm{m}$ diameter (Figures 1a and 1b), whereas morphology of MRS showed irregular particles with diameter size about 58 - $156 \mu \mathrm{m}$ (Figures $1 c$ and 1d). MRS did not show starch grains and indented appearance of native RS.

\section{Thermal properties}

The DSC pattern of RS showed the temperature of onset, peak and end of gelatinization at 73.22, 75.45 and $79.70^{\circ} \mathrm{C}$, respectively, whereas MRS did not show gelatinization endotherm in the temperature range of $30-120{ }^{\circ} \mathrm{C}$ (Figure 2), due likely to changes in the internal structure of starch granule during the modification process.

\section{FTIR spectra}

RS and MRS showed similar spectra below 800 $\mathrm{cm}^{-1}$ (Figure 3), which is the fingerprint region of starch. This region exhibited the complex vibration mode due to the skeletal mode vibration of glucose pyranose ring [13,14]. MRS showed an obvious change of the peak in the region of 950 - $900 \mathrm{~cm}^{-1}$ when compared with RS, suggesting an alteration of skeletal mode vibration of $\alpha-1,4$ glycosidic linkage [14]. Moreover, MRS and RS gave similar peaks at approximately 1020, 1079 and $1155 \mathrm{~cm}^{-1}$, corresponding to $\mathrm{C}-\mathrm{O}-\mathrm{H}$ and $\mathrm{CH}_{2}-\mathrm{O}-\mathrm{CH}_{2}$ bonds of glucose structures $[13,15,16]$. These results 
suggested that the backbone glucose units of starch were not changed after modification. The peak of RS at $1370 \mathrm{~cm}^{-1}$ originating from $\mathrm{CH}_{2}$ bending was shifted to higher wavenumber (1399 $\mathrm{cm}^{-1}$ ). This peak represented a modification of starch chain. The peak at $1648 \mathrm{~cm}^{-1}$ of RS was shifted to a lower wave number $\left(1594 \mathrm{~cm}^{-1}\right)$. This was attributed to the water adsorbed in the amorphous region of starch granules [13,14], leading to a change of crystallinity of RS from crystalline to amorphous form after treatment. In addition, a shift of the peaks of $\mathrm{C}-\mathrm{H}$ and $\mathrm{O}-\mathrm{H}$ stretching of RS $\left(2930\right.$ and $3393 \mathrm{~cm}^{-1}$, respectively) suggested that change of structure and hydrogen bonding in RS occurred after preparation process [17].
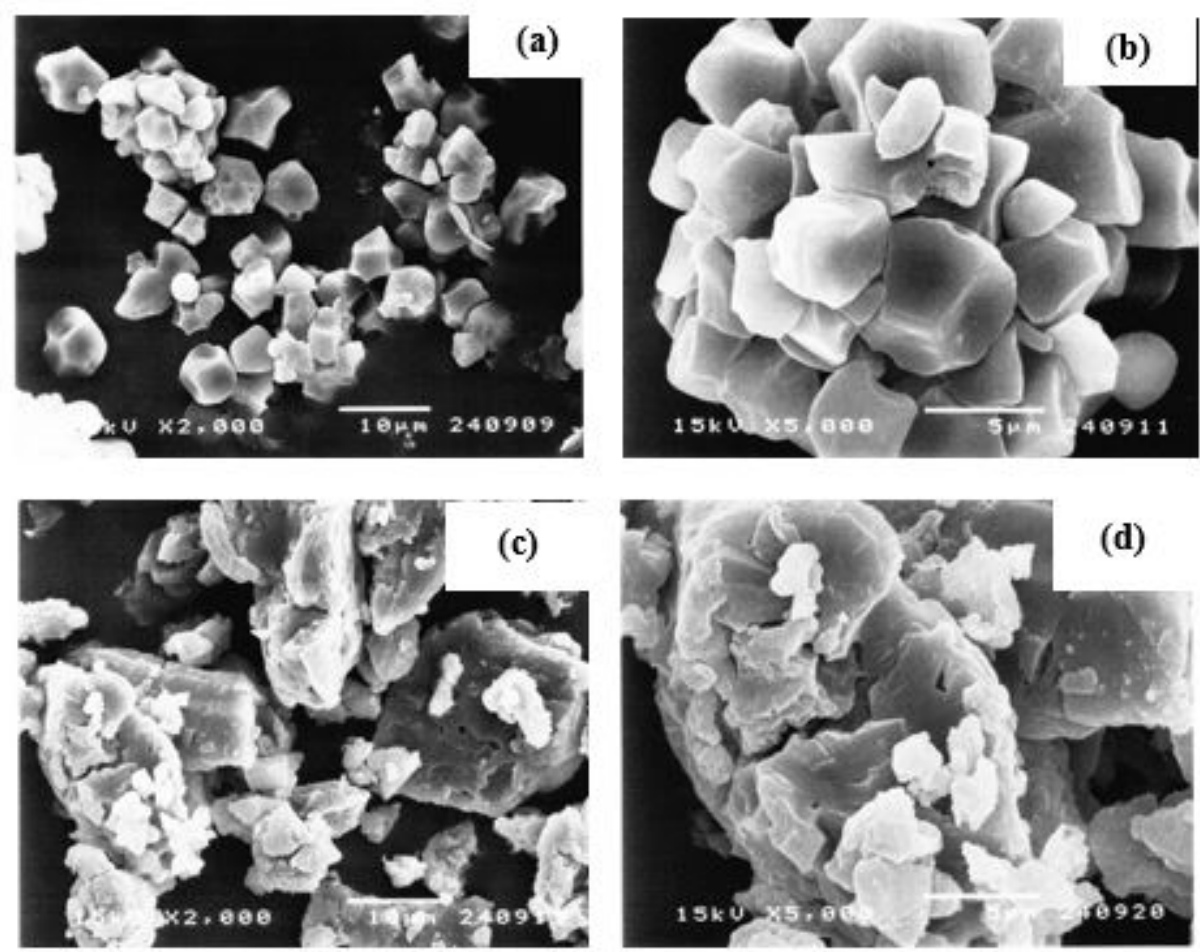

Figure 1: Particle morphology of RS at 2000x magnification (a) 5000x magnification (b); and MRS at 2000x magnification (c), 5000x magnification (d)

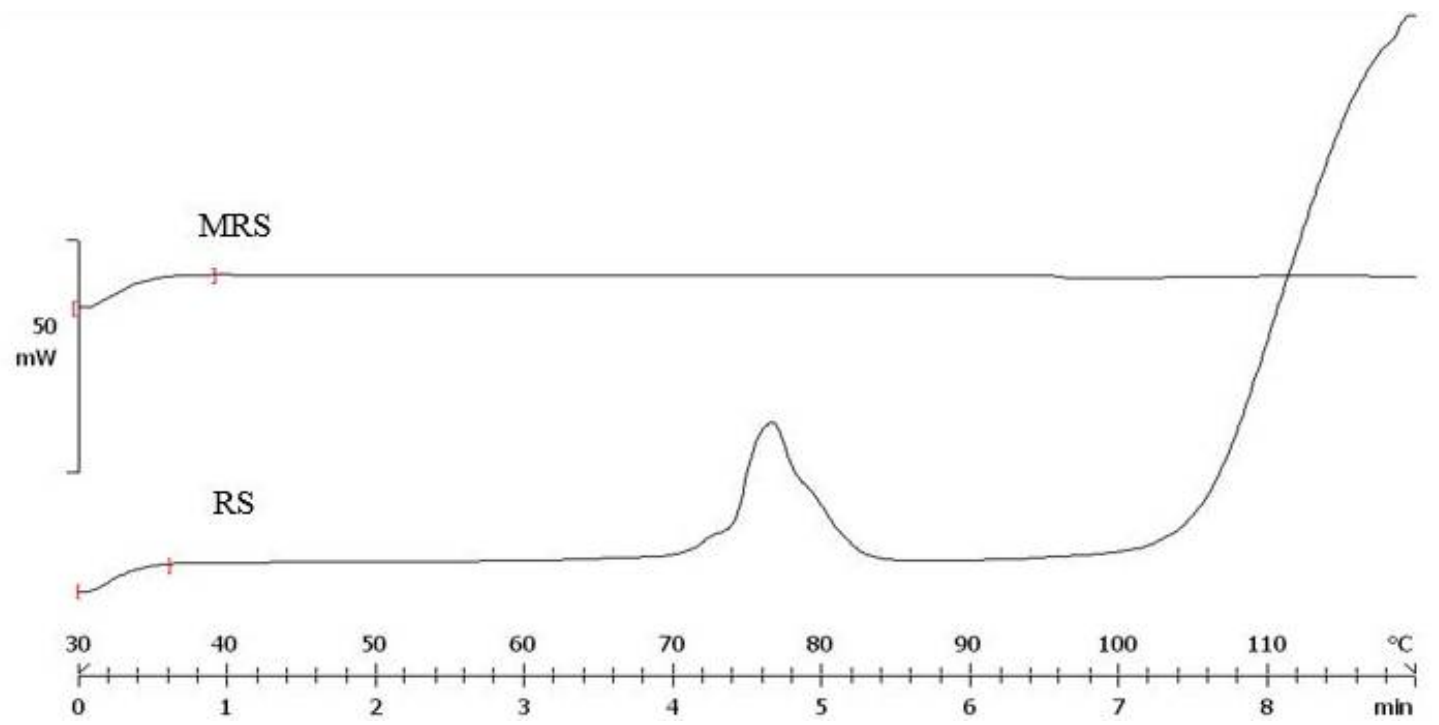

Figure 2: DSC thermograms of RS and MRS 


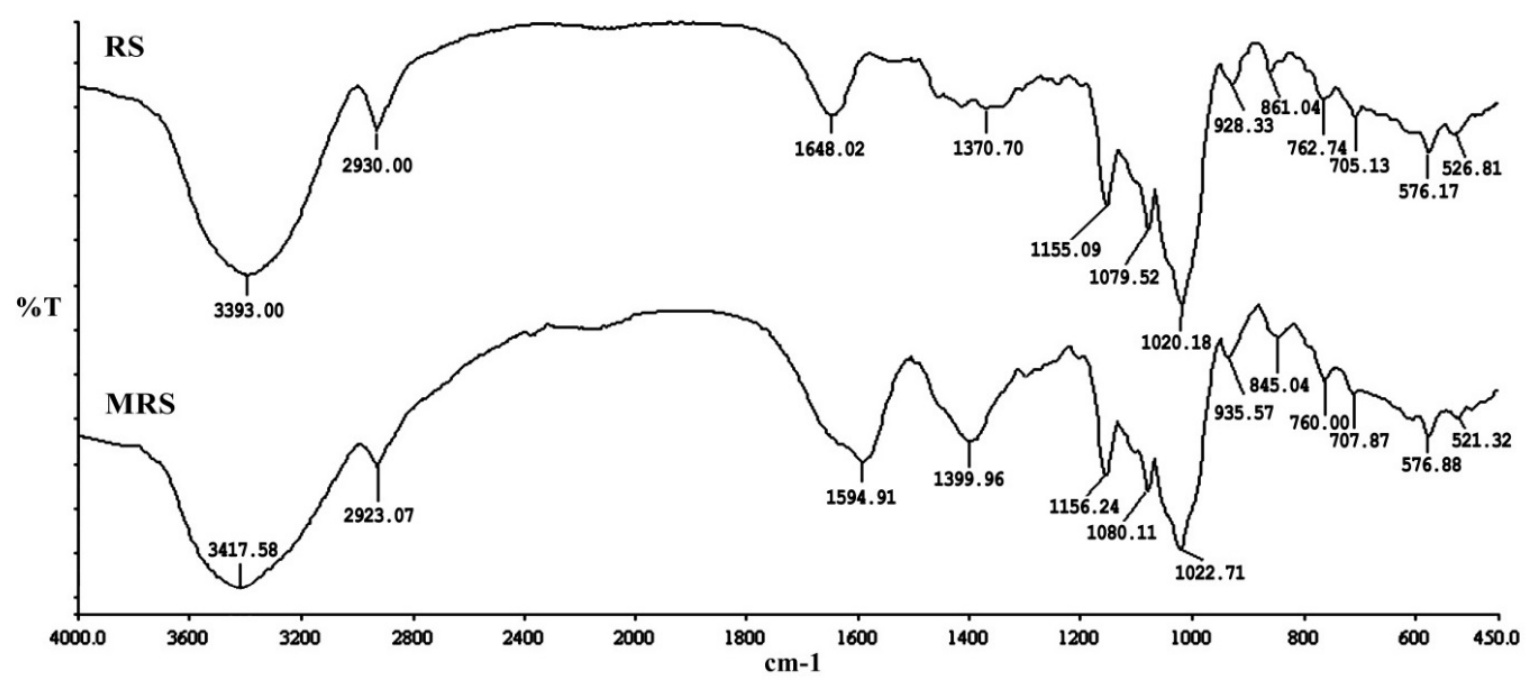

Figure 3: FTIR spectra of RS and MRS

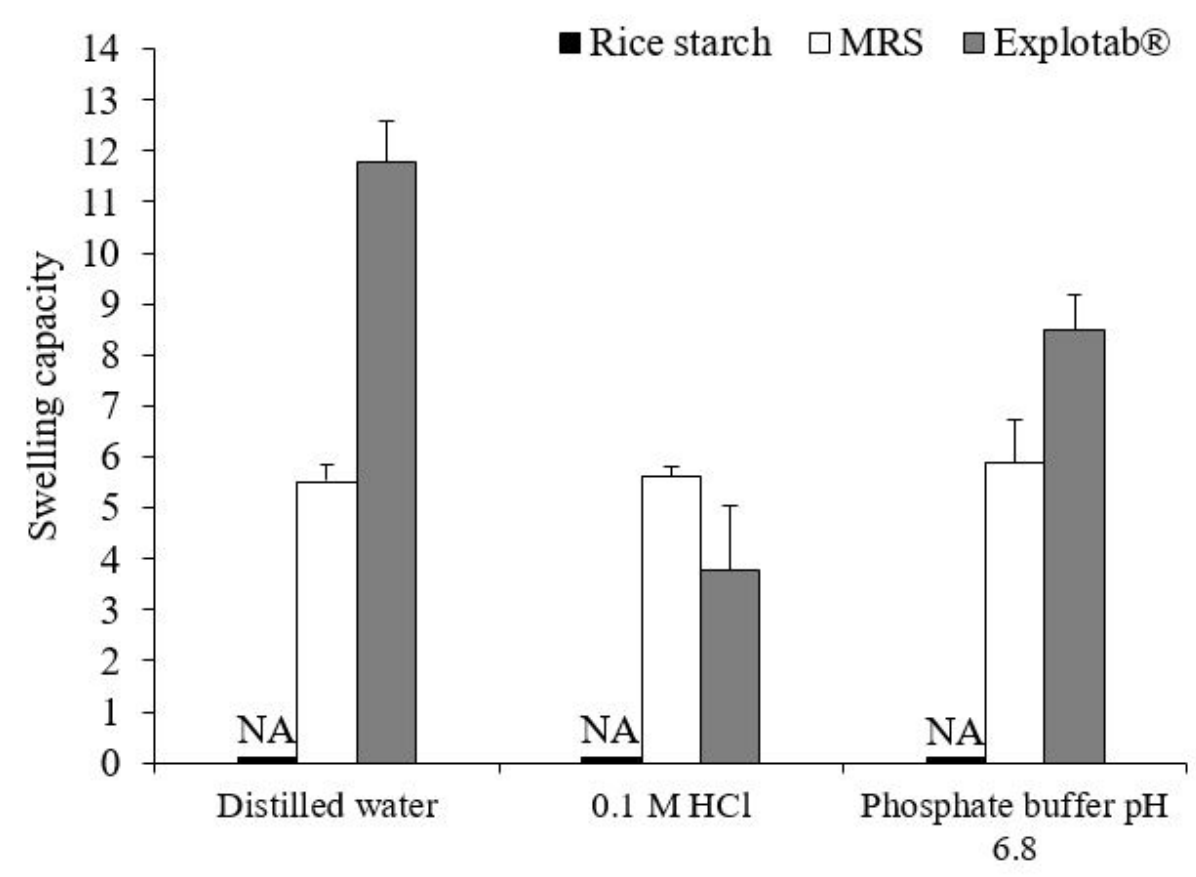

Figure 4: Swelling capacity of RS, MRS and $\operatorname{Explotab~}^{\circledR}$ in various media

\section{Swelling capacity}

RS did not swell in all media used (Figure 4) because the tight packing of amylose and amylopectin chain of RS obstruct water penetration [19]. On the other hand, MRS revealed a $\mathrm{pH}$-independent swelling and the swelling capacity of MRS was statistically higher $(p<0.05)$ than that of RS, whereas Explotab $\AA$ showed better swelling than MRS in water and phosphate buffer system but less in acid medium. These findings suggested that MRS had strong potential for use as a disintegrant in tablets.

\section{Characteristics of tablets containing MRS}

MRS was used as a tablet disintegrant and compared with RS and Explotab $\AA$ (Table 1). The hardness of tablet was not significantly different $(p>0.05)$. The friability of tablet without disintegrant was lower than those of tablets with disintegrant. The tablets containing MRS gave statistically shorter disintegration time $(p<0.05)$ than those containing RS, but the use of Explotab $\circledast$ resulted in a very short disintegration time. 
Table 1: Effect of various ingredients on physical properties of tablets using MRS as a disintegrant

\begin{tabular}{|c|c|c|c|}
\hline Tablet ingredient & Hardness (kp) & Friability (\%) & Disintegration time (min) \\
\hline \multicolumn{4}{|l|}{ Disintegrant } \\
\hline None & $4.16 \pm 0.25$ & 2.27 & $>180$ \\
\hline RS & $4.26 \pm 0.27$ & 2.36 & $26.03 \pm 4.99$ \\
\hline MRS & $4.32 \pm 0.23$ & 2.61 & $3.75 \pm 0.41$ \\
\hline Explotab $^{\circledR}$ & $4.02 \pm 0.18$ & 2.70 & $0.84 \pm 0.09$ \\
\hline \multicolumn{4}{|l|}{ MRS particle size } \\
\hline$<75 \mu \mathrm{m}$ & $4.36 \pm 0.17$ & 2.25 & $4.67 \pm 0.68$ \\
\hline $75-106 \mu \mathrm{m}$ & $4.32 \pm 0.23$ & 2.61 & $3.75 \pm 0.41$ \\
\hline $106-150 \mu \mathrm{m}$ & $4.06 \pm 0.19$ & 2.81 & $3.55 \pm 0.56$ \\
\hline \multicolumn{4}{|l|}{ MRS content (\%) } \\
\hline 2 & $3.90 \pm 0.12$ & 2.98 & $3.16 \pm 0.44$ \\
\hline 4 & $4.18 \pm 0.30$ & 2.29 & $1.42 \pm 0.23$ \\
\hline 8 & $4.30 \pm 0.23$ & 2.34 & $1.03 \pm 0.06$ \\
\hline \multicolumn{4}{|l|}{ Filler type } \\
\hline Di-comprez ${ }^{\circledR}$ & $3.90 \pm 0.12$ & 2.98 & $3.16 \pm 0.44$ \\
\hline Strach $1500^{\circledR}$ & $8.80 \pm 0.50$ & 0.40 & $16.32 \pm 2.36$ \\
\hline Super-tab ${ }^{\circledR}$ & $6.02 \pm 0.36$ & 1.92 & $1.55 \pm 0.16$ \\
\hline \multicolumn{4}{|c|}{ Lubricant content (\%) } \\
\hline 1 & $3.90 \pm 0.12$ & 2.98 & $3.16 \pm 0.44$ \\
\hline 3 & $4.22 \pm 0.16$ & 3.07 & $8.09 \pm 1.65$ \\
\hline 5 & $4.82 \pm 0.24$ & 2.38 & $31.68 \pm 1.72$ \\
\hline \multicolumn{4}{|l|}{ Drug type } \\
\hline PPNL & $4.00 \pm 0.14$ & 2.36 & $2.23 \pm 0.16$ \\
\hline HCTZ & $3.82 \pm 0.11$ & 2.47 & $0.82 \pm 0.12$ \\
\hline
\end{tabular}

Particles size of MRS influenced physical properties of tablets. Increase of MRS particles size caused lower hardness, higher friability and shorter disintegration time (Table 1, rows 7 - 10). Effect of MRS content on tablets was also investigated (Table 1). Increasing MRS content resulted in increased hardness of tablet while disintegration time was decreased.

MRS was used as a disintegrant of tablets prepared using different fillers (Table 1, rows 15 18). Starch $1500 \AA$ and Super-tab® provided higher hardness tablets than Di-comprez®. The friability of Di-comprez ${ }^{\circledR}$ was the highest. Tablet

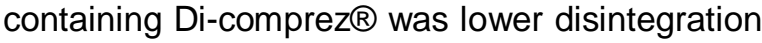
time than tablet containing Starch $1500 \AA$ over 5 times. Thus, filler type affected properties of tablets, especially disintegration time. Moreover, magnesium stearate, which used as lubricant, also affected properties of tablets containing MRS. Hardness and disintegration time were significantly increased $(p<0.05)$ with increasing magnesium stearate content (Table 1, row 1922), whereas friability of tablets tended to decrease with higher magnesium stearate content.

The properties of tablets containing PPNL and HCTZ, high and low water solubility drugs, respectively, were studied (Table 1). Hardness and friability of PPNL and HCTZ tablets were not significantly different $(p>0.05)$. Disintegration time of HCTZ was significantly lower $(p<0.05)$ than PPNL. Moreover, dissolution profile of both tablets is shown in Figure 5 . $T_{50 \%}$, i.e. the time to achieve $50 \%$ drug dissolved, of PPNL and HCTZ tablets was $2.54 \pm 0.17$ and $11.15 \pm 1.15$ min, respectively, due probably to the difference in drug solubility.

\section{DISCUSSION}

The morphology and particles size of RS obtained were similar to that reported by other researchers [18,19]. However, MRS did not appear as granules likely because they were swollen and ruptured during modification process $[6,8,20]$. The complex structure of RS consists of long chain amylose linked with branch chain amylopectin. The proton of $\mathrm{OH}$ group may dissociate leaving negative charges on the starch molecules after treatment with strong base $(\mathrm{NaOH})$. The repulsion between negative charges leads to swelling after water absorption. Then, dissociation of double-helix regions of starches lead to breakdown and change of crystalline structure, and the distortion of starch morphology [8,9]. This structural change following alcoholic-alkaline treatment, causing the disappearance of gelatinization endotherm $[8,9,19]$, was confirmed by FT-IR analysis of position and intensity of infrared band for RS and MRS [21,22]. The intensity of $\alpha-1,6$ glycosidic linkage of the amylopectin $\left(\mathrm{CH}_{2}\right.$ bonding around $1399 \mathrm{~cm}^{-1}$, and $\mathrm{OH}$ stretching around $3417 \mathrm{~cm}^{-1}$ ) of MRS was lower than RS. 


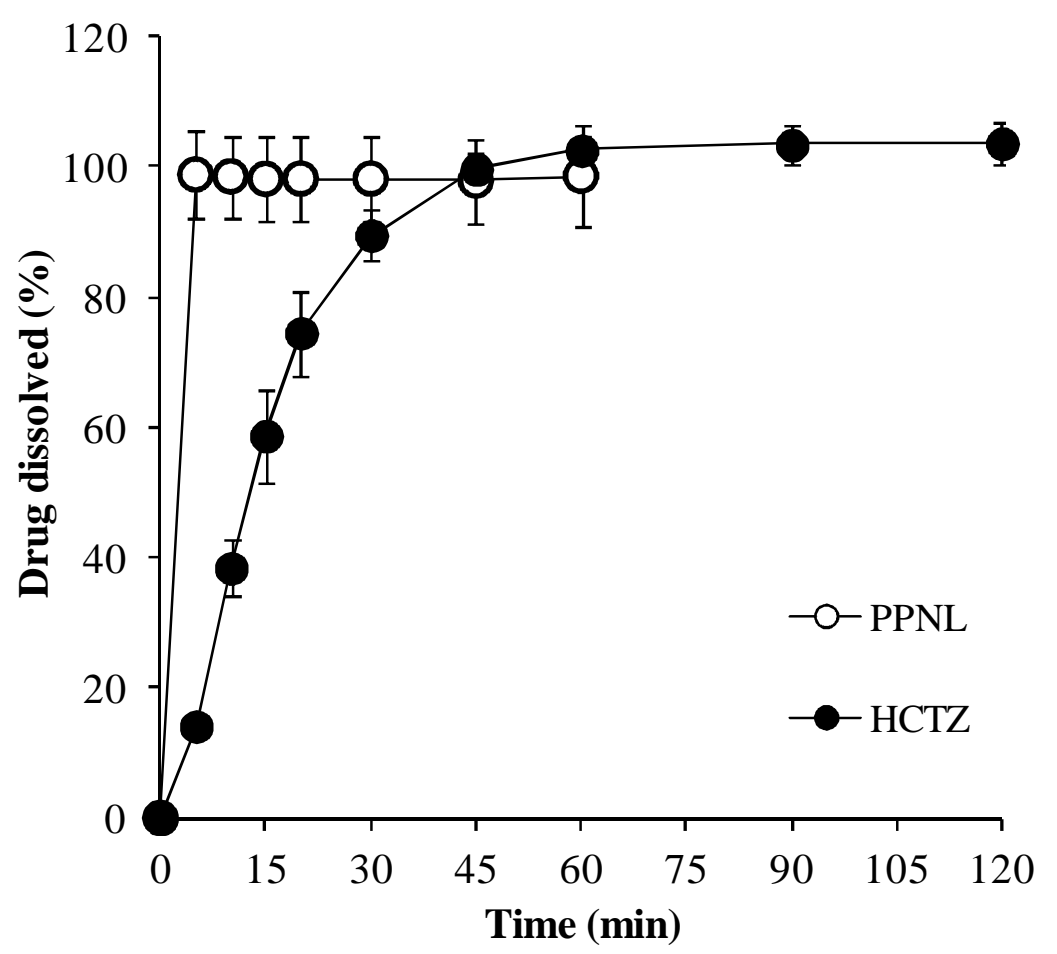

Figure 5: Dissolution profiles of PPNL and HCTZ tablets containing $4 \% \mathrm{w} / \mathrm{w}$ MRS as a disintegrant

Moreover, the amorphous region of starch where water molecules could be tightly adsorbed (around $1594 \mathrm{~cm}^{-1}$ ) showed a low absorption, resulting in decreased crystallinity degree of MRS. The molecule of water can interact easier with MRS, resulting in viscosity, swelling and solubility improvement with respect to RS [8]. Consequently, MRS provided better $\mathrm{pH}$ independent swelling capacity than RS.

MRS was used as a tablet disintegrant in comparison with RS and Explotab®, a low substituted carboxy methyl starch (superdisintegrants). MRS showed shorter disintegration time than RS because of higher swelling capacity. Polymer swelling is one of the mechanisms of tablet disintegration; rapid water absorption and swelling of disintegrant caused a break of tablet to smaller particles for enhancing drug dissolution [23]. However, MRS gave longer disintegration time than Explotab $\AA$, because of lower swelling capacity of MRS. For particles size of MRS, tablet containing smaller particles of MRS had the highest hardness and the lowest friability because of tightly packing with other ingredients in the tablet. The closed packing of particles caused a retardation of water absorption and swelling of MRS, resulting in longer disintegration time of tablets.

Furthermore, tablet properties were strongly influenced by MRS content. Increase of MRS gave greater hardness and lower friability of the tablets, exhibiting important benefits over native
RS. Moreover, higher disintegrant content allows a rapid uptake of water followed by fast and significantly higher swelling, leading to tablets break up in shorter time. In particular, the highest content (8\%) of MRS showed the best disintegration action in this study.

Tablet properties were dependent upon the filler added. Various types of fillers, such as Dicomprez ${ }^{\circledR}$, Starch $1500 \AA$ and Super-Tab ${ }^{\circledR}$, were used in this study. The tablets containing Supertab®, lactose anhydrous, had lower disintegration time than those containing Dicomprez $\circledast$, dibasic calcium phosphate, because water absorption may occur rapidly in tablets prepared using hydrophilic fillers. However, the highest disintegration time was found in the tablets containing Starch $1500 \AA$. Starch $1500 \AA$ is a partially pregelatinized maize starch that can be partially swollen in water. The swelling of Starch $1500 \AA$ may retard water absorption and then reduce the MRS efficiency for tablet disintegrant. Moreover, the greatest tablet hardness of the tablet containing Starch $1500 \AA$ may also affect the disintegration time.

Lubricant effect is essential in developing a suitable excipient for tablets. In this study, increase in magnesium stearate content provided higher hardness, but lower friability of tablets was obtained. The disintegration time of the tablets significantly increased with increasing magnesium stearate content. These results indicate that the hydrophobicity of magnesium 
stearate retarded the absorption of water and polymer swelling which strongly influenced disintegration time, and this is in agreement with the findings of Wang et al [24].

MRS was used as a disintegrant in PPNL and HCTZ tablets. The results showed that MRS gave high disintegration efficiency in both tablets, and the disintegration time was in the range of 0.82 - $2.23 \mathrm{~min}$. HCTZ tablets showed faster disintegration time than PPNL tablets. Tablet disintegration normally promotes drug dissolution. However, HCTZ tablets showed slower dissolution rate than PPNL due probably to the lower water solubility of HCTZ.

\section{CONCLUSION}

Alcoholic-alkaline treatment changes the structure and properties of RS. The disruption of molecular bonding within the crystalline structure of starch confers enhanced characteristics on MRS, relative to native RS, including higher water solubility and swelling behavior, and faster disintegration. Consequently, MRS has a strong potential for use as an effective disintegrant in directly compressed tablets.

\section{ACKNOWLEDGEMENT}

This research was supported by Higher Education Research Promotion and National Research University Project of Thailand, Office of the Higher Education Commission, through Food and Functional Food Research Cluster of Khon Kaen University, Graduate School, Khon Kaen University, Faculty of Pharmaceutical Sciences, Khon Kaen University, Thailand. The English language of the manuscript was edited by Professor Thaned Pongjanyakul and Associate Professor Aroonsri Priprem, Khon Kaen University, Khon Kaen, Thailand.

\section{REFERENCES}

1. Gibson M, Ed. Pharmaceutical Preformulation and Formulation. 2nd edn. New York: Informa Healthcare; 2009.

2. Nattapulwat N, Purkkao N, Suwithayapanth O. Evaluation of Native and Carboxymethyl Yam (Dioscorea esculenta) Starches as Tablet Disintegrants. Silpakorn U Science and Tech J 2008; 2(2): 18-25.

3. Lieberman HA, Lachman L, Eds. Pharmaceutical Dosage Forms: Tablets Volume1. New York: Marcel Dekker; 1980.

4. Rashid I, Al-Remawi M, Leharne SA, Chowdhry BZ, Badwan A. A novel multifunctional pharmaceutical excipient: Modification of the permeability of starch by processing with magnesium silicate. Int J Pharm 2011; 411: 18-26.

5. Aulton ME, editor. Pharmaceutics: The science of dosage form design. Edinburgh: Churchill Livingstone; 1988.

6. Chen J, Jane J. Preparation of granular cold-watersoluble starches by alcoholic-alkaline treatment. Cereal Chem 1994a; 71(6): 618-622.

7. Kaur B, Ariffin F, Bhat R, Karim AA. Progress in starch modification in the last decade. Food Hydrocolloids 2012; 26: 398-404.

8. Chen J, Jane J. Properties of granular cold-water-soluble starches prepared by alcoholic-alkaline treatments. Cereal Chem 1994b; 71(6): 623-626.

9. Kaur B, Fazilah A, Kalim AA. Alcoholic-alkaline treatment of sago starch and its effect on physicochemical properties. Food Bioprod Process 2011; 89(4): 463-471.

10. Mohanachandran PS, Sindhumol PG, Kiran TS. Superdisintegrants: an overview. Int J Pharm Sci Rev Res 2011; 6(1): 105-109.

11. Mitrevej A, Sinchaipanid N, Faroongsarng D. Spray-dried rice starch: comparative evaluation of direct compression fillers. Drug Dev Ind Pharm 1996; 22(7): 587-594.

12. United States Pharmacopoeia 34: The National Formulary 29; United States Pharmaceutical Convention, Inc. 2011.

13. Huang $C B$, Jeng $R$, Sain $M$, Saville $B A$, Hubbes $M$. Production, characterization and mechanical properties of starch modified by Ophiostoma spp. BioRes 2006; 1(2): 257-269.

14. Kizil R, Irudayaraj J, Seetharaman K. Characterization of irradiated starches by using FT-Raman and FTIR spectroscopy. J Agric Food Chem 2002; 50: 3912-3918.

15. You L, LU F, Li D, Qiao Z, Yin Y. Preparation and flocculation properties of cationic starch/chitosan crosslinking-copolymer. J Hazard Mater 2009; 172: 3845.

16. Lanthong $P$, Nuisin $R$, Kiatkamjornwong $S$. Graft copolymerization, characterization, and degradation of cassava starch-g-acrylamide/itaconic acid superabsorbents. Carbohydr Polym 2006; 66: 229-245.

17. Kar B, Sahoo H, Rath SS, Das B. Investigations on different starches as depressants for iron ore flotation. Miner Eng 2013; 49: 1-6.

18. Olayemi OJ, Oyi AR, Allagh TS. Comparative evaluation of maize, rice and wheat starch powers as pharmaceutical excipients. Niger J Pharm Sci 2008; 1(7): 131-138.

19. Singh N, Singh J, Kaur L, Sodhi NS, Gill BS. Morphological, thermal and rheological properties of starches from different botanical sources. Food Chem 2003; 81: 219-231.

20. Yan $H$, Zhengbiao GU. Morphology of modified starches prepared by different methods. Food Res Int 2010; 43(3): 767-772.

21. Lizuka K, Aishima T. Starch gelation process observed by FT-IR/ATR spectrometry with multivariated data analysis. J Food Sci 1999; 64 (4): 653-658.

Trop J Pharm Res, February 2016; 15(2): 228 
22. Bellon-Maurel V, Vallat $C$, Goffinet $D$. Quantitative analysis of individual sugars during starch hydrolysis by FT-IR/ATR spectrometry Part I: Multivariate calibration study—repeatability and producibility. J Appl Spectros 1995; 49: 556-562.
23. Mangal $M$, Thakral S, Goswami $M$, Ghai $P$. Superdisintegrants: An updated review. Int $J$ Pharm Pharm Sci Res 2012; 2(2): 26-35.

24. Wang J, Wen $H$, Desai D. Lubrication in tablet formulations. Eur J Pharm Biopharm 2010; 75: 1-15. 